\title{
A EDUCAÇÃO CONTEXTUALIZADA E A FORMAÇÃO DO SUJEITO: PARA ALÉM DA APRENDIZAGEM ESCOLAR
}

\author{
Antunes, Arnon Marques \\ Bacharelando Interdisciplinar em Humanidades / IHAC/ \\ UFBA, arnon.marques.antunes@gmail.com \\ Santos, Gervásio Ferreira \\ Doutor do Departamento de Ciências Econômicas, FCE/ \\ UFBA, gervasiofsantos@gmail.com \\ Lordêlo, José Albertino Carvalho \\ Doutor em Educação e Professor aposentado da Faculdade \\ de Educação, UFBA, jalbert@ufba.br \\ Fonseca e Gomes, Ludmila de Sá \\ Mestre em Economia Aplicada, USP. \\ Informações do artigo \\ Recebido em 09/05/2017 \\ Aceito em 07/12/2017
}

\begin{abstract}
Resumo
Este texto aborda os resultados obtidos por um projeto desenvolvido no âmbito escolar rural do semiárido baiano, para além dos muros da instituição. A metodologia, de inspiração freiriana, foi alicerçada no ensino socialmente referenciado na realidade do aluno. De acordo com os princípios desta metodologia, o aluno deve conhecer, analisar e transformar (Projeto CAT) a realidade do campo onde vive. A contextualização do conhecimento é fundamental para que o aluno possa ressignificar saberes e valores, possa aprender a viver, ler e intervir em sua realidade. Este sujeito ativo viria por meio da formação continuada dos professores, da produção de material didático contextualizado e da adoção de práticas pedagógicas e de gestão democrática. Ainda como produto institucionalizado, pretendia-se convencer os municípios a destacar recursos do orçamento local para utilizar a referida metodologia de educação do campo contextualizada. A técnica de análise que produziu a presente discussão foi ancorada no modelo estatístico-econométrico de análise de regressão para isolar o efeito do programa a partir da coleta de dados entre grupos de tratamento e controle. Os resultados mostraram que houve diferenças estatísticas significativas entre escolas que adotaram e que não adotaram a metodologia. Propõese que a educação contextualizada se justifique pelos seus resultados em indicadores objetivos para além dos muros da escola, por um princípio de direito do sujeito em compreender o seu lugar e as relações que se estabelecem a partir dele nos vários planos da vida: social, político, econômico, ambiental e cultural.

Palavras-chave: educação do campo; educação contextualizada.
\end{abstract}

\section{Introdução}

A importância e a extensão da escolarização no processo de preparação da criança e do jovem para a vida adulta é recente. Os projetos de escolarização universal têm sido levados a cabo há pouco mais de um século e os ideais iluministas que os estruturaram (como a ênfase na universalidade dos conteúdos e na condição igualitária de acesso a eles pelo uso da razão) datam de poucos séculos. A educação, portanto, prescinde da escola, realiza-se em outras instituições e ganha formas muito diferentes em cada contexto social. Cabe não confundir educação e escolarização: a arquitetura do edifício escolar, as relações de poder que ali se estabelecem e os discursos ali (re)produzidos são parte de uma das formas presentes de 
educação, que deve sua existência e centralidade às relações sociais de que participa e à forma como o faz. No Ocidente, e, colocando de maneira muito breve para atender aos objetivos deste texto, poderíamos situar os embriões do atual sistema de ensino em demandas políticoeconômicas do Estado burguês, como mão-de-obra minimamente qualificada (e disciplinada) e difusão da narrativa nacional que legitimasse seu domínio territorial, de um lado; por outro lado, poderíamos relacionar a história do atual sistema de ensino às reivindicações por direitos das classes populares que acompanham a modernidade ocidental.

A participação do sistema de ensino nos processos de socialização é um tema recorrente na sociologia, analisado e reinterpretado no interior da disciplina desde os trabalhos clássicos do século XIX. Não cabe aqui uma ampla revisão desta literatura, mas é importante destacarmos alguns pontos. Recorrendo a BOURDIEU e PASSERON (1982), pode-se iniciar destacando que, em qualquer formação social, uma ação pedagógica "é objetivamente uma violência simbólica, enquanto imposição, por um poder arbitrário, de um arbitrário cultural" (p.20). A noção de "arbitrário", aqui, indica que "as estruturas e as funções dessa cultura não podem ser deduzidas de nenhum princípio universal, físico, biológico ou espiritual, não estando unidas por nenhuma espécie de relação interna à 'natureza das coisas' ou a uma 'natureza humana'"' (p.23). Em outros termos, a noção de arbitrariedade visa destacar que a cultura e o poder que se impõem em uma ação pedagógica são frutos de relações histórica e socialmente situadas, ou seja, concomitantemente não naturais e não gratuitas.

Os conceitos de capital e habitus compõem a teoria do espaço social de Bourdieu, que rompe com as representações tradicionais da hierarquia social fundada em esquemas piramidais (BONNEWITZ, 2003, p.52). Segundo BOURDIEU (1989, p.135), os agentes distribuem-se no espaço social " [...] na primeira dimensão, segundo o volume global do capital que possuem e, na segunda dimensão, segundo a composição do seu capital - quer dizer, segundo o peso relativo das diferentes espécies no conjunto das suas posses". Assim, Bourdieu estabelece o volume e a composição de capital como critérios fundamentais para estimação da distância/proximidade entre as posições ocupadas pelos agentes, colocando em relevo dois tipos de capital, econômico e cultural (os outros são social e simbólico), como importantes critérios diferenciadores de três grandes "regiões" deste espaço social : as classes sociais dos dominantes, da pequena burguesia e dos populares. 
Além deste nível estrutural vinculado à posse de capital, Bourdieu associa a vinculação de classe dos agentes ou grupos ao habitus de classe formado ao longo dos processos de socialização. Nas palavras do autor:

[...] as representações dos agentes variam segundo sua posição (e os interesses que estão associados a ela) e segundo seu habitus como sistema de esquemas de percepção e apreciação, como estruturas cognitivas e avaliatórias que eles adquirem através da experiência durável de uma posição do mundo social. O habitus é ao mesmo tempo um sistema de esquemas de produção de práticas e um sistema de esquemas de percepção e apreciação das práticas. E, nos dois casos, suas operações exprimem a posição social em que foi construído. (BOURDIEU, 2004, p 158).

É desta maneira que se relacionam o processo de socialização decorrente da posição de classe e o habitus. Neste texto, trata-se, sobretudo, do habitus decorrente da incorporação de capital cultural. O capital cultural em estado incorporado, nos termos de BOURDIEU (2007, pp. 74-75), " é um ter que se tornou ser, uma propriedade que se fez corpo e tornou-se parte integrante da 'pessoa', um habitus".

O sistema de ensino regular, característico da formação social em que se desenvolve o projeto Conhecer, Analisar e Transformar-CAT, também exerce violência simbólica, impondo, difundindo e inculcando, pelo tecido social, as significações que compõem a cultura arbitrária das classes dominantes. Algumas características que ilustram a orientação de classe do processo de escolarização são as políticas explícitas do currículo (seleção das significações alçadas à categoria de "saber legítimo") e o habitus de classe valorizado pelos processos de avaliação e seleção (formais e informais) da escola. Ambas as características contribuem para que o sistema de ensino exerça uma de suas principais funções: "a justificação ideológica da ordem que ele reproduz por seu funcionamento" (BOURDIEU e PASSERON, 1982, p.215). Vejamos, brevemente, como o exercício desta função torna-se possível.

O lugar primeiro da socialização do sujeito é a família. Nela, a criança, desde o nascimento, aprende os padrões de comportamento e conduta, hábitos, usos, costumes, valores, atitudes, um padrão de linguagem. É a família que promove a construção das bases da subjetividade, da personalidade e da identidade, segundo Rosa (2001). Este processo de socialização, em que a família age em nome da sociedade, moldando o novo membro desde o seu nascimento, Durkhein (1984) qualificou de primário. Já o processo de socialização secundária é de responsabilidade, sobretudo, da escola. Em uma sociedade de classes de amplas desigualdades, como a brasileira, tais sistemas de formação se diferenciam em função de uma distribuição muito desigual de capitais (sobretudo econômico e cultural) 
entre as classes. Assim, os processos de socialização primária se diferenciam entre as classes sociais e "entregam" para a escola sujeitos com habitus primários com forte orientação de classe. Em suma, diferentes sistemas de formação familiares atuam na socialização primária dos sujeitos e isto pode resultar em convergência ou conflito entre o habitus primário e as exigências escolares. ${ }^{1}$

Se os habitus se diferenciam, o sistema de ensino regular valoriza, prioritariamente, aqueles convergentes com as disposições e percepções valorizadas pela classe burguesa. Neste sentido, sujeitos que vivenciam a socialização primária em famílias que dispõem de capitais cujo volume e composição atendem a critérios de valorização das classes dominantes tendem a desenvolver habitus primários valorizados pela escola - em outros termos, sua escolarização é vivenciada como continuidade da formação familiar. Ao contrário, sujeitos que não dispõem de capital familiar valorizado na escola a ser "herdado" na socialização primária tendem a enfrentar a escolarização como um processo mais conflituoso, de disputa entre diferentes sistemas de valores, como ilustrado por Toscano (2001):

\begin{abstract}
...a criança perceberá, por sua própria experiência, que, se continuar a observar aqueles valores ao pé da letra, só terá prejuízos. Depois de algumas experiências negativas, ou ela se recolhe inteiramente à família e se marginaliza de outro grupo, por considerá-lo corrompido, indigno de qualquer consideração, ou minimiza os valores transmitidos pela família e adere ao grupo, entrando em choque inevitável com os parentes. (TOSCANO, 2001, p 112)
\end{abstract}

São, principalmente, os sujeitos oriundos de famílias de volume e composição de capital menos valorizados pela escola que sofrem os efeitos da violência simbólica no sistema de ensino. Munidos de percepções e disposições divergentes daquelas valorizadas nos processos de avaliação (formais e informais) e alçadas à posição de saber legítimo pela seleção curricular e formação docente, sujeitos das classes populares tendem a receber estigmas como "maus alunos" (em oposição aos "bons" e mais relacionados às disposições e percepções morais) ou "esforçados" (em oposição aos "brilhantes" e relacionados às disposições cognitivas), sendo menos valorizados socialmente e diminuindo suas possibilidades de mobilidade social. Assim, o ensino exerce a função ideológica de justificação e legitimação da ordem, além do ocultamento de sua orientação de classe.

A estrutura do sistema de ensino brevemente descrita acima indica uma tendência de reprodução social associada à reprodução cultural sem, no entanto, se realizar de maneira

\footnotetext{
1 O leitor interessado poderá encontrar uma leitura introdutória à teoria reprodutivista do sistema educacional
} de Boudieu em BONNEWITZ (2003) e NOGUEIRA e NOGUEIRA (2002). 
determinística: existem espaços, brechas para agências que possibilitam alterações da ordem. Uma dessas brechas a ser explorada está na relação professor-aluno, com o recurso às práticas pedagógicas menos impositivas e mais dialógicas, como as propostas por Paulo Freire, por exemplo. A distância entre as referências e experiências dos educandos (sobretudo das classes populares) e as ações pedagógicas do ensino regular são destacadas pelo intelectual pernambucano no conceito de educação bancária. Freire destaca que a proposta do ensino regular concebe o saber como posse exclusiva do professor, que deve transmiti-lo ao aluno; este, cuja agência é negada pelo processo de ensino-aprendizagem tradicional, tem o seu arcabouço de experiências e vivências desconsiderado, quando não peremptoriamente desqualificado no processo de escolarização (FREIRE, 1970).

Torna-se possível, assim, uma aproximação entre o conceito de educação bancária em Freire e o de violência simbólica em Bourdieu e Passeron. Ao desconsiderar os processos de socialização anteriores ao instante da relação de ensino-aprendizagem, a educação bancária restringe seu universo de interlocutores àqueles previamente socializados em seu sistema de significações pela ação de outras instituições, como a família. São estes sujeitos, sobretudo, que deterão as disposições, os modos de agir e o repertório de referências (em suma, o habitus) adequados para dar sentido às informações e experiências de sala de aula. Assim, na educação bancária, prática pedagógica e política curricular contribuem para a imposição de um arbitrário cultural que reproduz e legitima a ordem social.

O projeto CAT atua justamente nesse contexto, tendo como público participante sujeitos submetidos à violência simbólica do sistema regular de ensino: crianças matriculadas no primeiro ciclo do ensino fundamental em escolas da zona rural do semiárido baiano. Nesse contexto, dentre as intervenções do projeto destacam-se a reivindicação por um currículo contextualizado e a atuação direta em formação docente, através das coordenações pedagógicas do projeto. Ambas as ações convergem na construção de uma alternativa de resistência à educação bancária e à violência simbólica, apontando para um horizonte político de mudança social.

\section{Hipóteses de pesquisa}

O primeiro ganho esperado com a execução do projeto CAT éo aumento da participação de egressos em instituições e grupos comunitários fora da escola, ganho sistematizado 
nesta pesquisa na categoria chamada "Ativismo". Entende-se que o CAT efetua um desvio em relação à escolarização padrão, ao destacar a necessidade de uma educação que forma sujeitos para a compreensão e intervenção social, sobretudo local. Espera-se, portanto, que esta proposta pedagógica se traduza em estímulo à participação em outras instâncias da vida comunitária. Destaque-se, por fim, que "Ativismo", aqui, não contempla uma análise do conteúdo político-ideológico desta participação: analisamos se os estudantes que passaram pelo CAT participam mais ou menos do que outros estudantes, mas não temos condições de fazer afirmações sobre o conteúdo desta participação.

Outra mudança esperada diz respeito à orientação "político-ideológica" dos estudantes, que recebeu aqui esta rubrica. Busca-se averiguar o impacto da metodologia na diminuição da tendência à reprodução cultural vigente no sistema de ensino regular. Para tanto, elencamos algumas questões que contemplam temas como política de drogas, de ações afirmativas, de segurança pública, diversidade sexual e de gênero e proteção ambiental, para, em seguida, posicionarmos os sujeitos CAT e não-CAT entre os polos "conservador" ou "liberal". Esperava-se que os egressos do projeto estivessem mais próximos do polo liberal, em comparação com os egressos que não participaram do projeto, haja vista a orientação político-pedagógica da proposta.

Estabelecemos, também, uma categoria denominada "Importância da escola" para aferir a importância que o egresso atribui à escolarização no primeiro ciclo do ensino fundamental em seu processo formativo. Espera-se que egressos do CAT atribuam maior importância a esta etapa da escolarização, já que a proposta político-pedagógica do CAT estimularia o educando a ressignificar suas práticas sociais, traduzindo em gestos novos (fora e depois da escola) seu novo saber.

Finalmente, a categoria "Fixação no Território" foi criada tendo em vista os possíveis impactos da ressignificação do Semiárido (que é um objetivo fundamental do projeto) nos planos de futuro dos egressos. O Território de Identidade é alvo frequente de discursos depreciativos, profundamente arraigados no imaginário local e nacional e, em grande medida, reproduzidos na escolarização tradicional. Em sentido contrário, o projeto CAT trabalha com discursos de enaltecimento de determinadas características locais, naturais e/ou culturais, que apontam para uma convivência sustentável no Semiárido. O alinhamento da política 
curricular contextualizada com estímulo à participação comunitária nos permite supor uma tendência maior, nos egressos CAT, para desejar que seu futuro se desenrole no Semiárido.

Na próxima seção, descrevemos o percurso metodológico trilhado na pesquisa.

\section{METODOLOGIA}

A perspectiva metodológica da pesquisa foi ancorada na abordagem quantitativa, com uma tentativa inicial de realização de um survey. Contudo, dadas as dificuldades relatadas na literatura para a localização de egressos, por LORDELO e DAZZANI (2012), a amostra final não se configurou como probabilística ou intencional, nos termos estritos da estatística. Foram constituídos dois grupos: um com egressos da metodologia CAT e outro de controle.

A pesquisa se valeu de fontes primárias, coletando dados diretamente dos sujeitos. Tendo em vista que a proposta pedagógica do CAT atribui importância decisiva à contextualização do saber na zona rural do semiárido baiano, o primeiro critério de seleção dos sujeitos que compuseram a amostra foi ter cursado o primeiro ciclo na zona rural do semiárido. Para que pudéssemos atribuir os resultados encontrados à metodologia CAT, estabelecemos, ainda, que apenas estudantes que cursaram todos os anos do primeiro ciclo em escola adepta ao CAT iriam compor este grupo. O segundo grupo, ou grupo de controle, também constituiu uma amostra. Em ambos os grupos, os sujeitos já haviam concluído o primeiro ciclo no momento da coleta.

A princípio, desejávamos trabalhar, apenas, com sujeitos que tivessem concluído o primeiro ciclo em anos específicos (2007, 2009, 2011 e 2013), anos de aplicação da prova Brasil. Esperávamos, com isso, relacionar os resultados encontrados com dados de aprendizagem produzidos pela referida avaliação nacional. Contudo, as dificuldades referentes ao período de viagem a campo e ao sítio de coleta nos fizeram abandonar esta intenção da pesquisa e, consequentemente, incluir na amostra sujeitos que concluíram o ciclo básico em anos distintos.

Os municípios onde se realizaram as coletas foram escolhidos em acordo com a organização executora, que disponibilizou apoio logístico, respeitando os critérios metodológicos. Dentre a vasta área de atuação do CAT, optamos por nos dirigir a dois territórios de identidade - do Sisal e da Bacia do Rio Jacuípe. Em cada território, selecionamos dois municípios, um CAT e um Não-CAT, como ilustrado na Tabela 1. 
Tabela 1 - Municípios escolhidos, território de identidade correspondente e atuação do CAT

\begin{tabular}{l|l|l}
\hline Grupo & Território do Sisal & Território da Bacia do Jacuípe \\
\hline CAT & Conceição do Coité & $\begin{array}{l}\text { Riachão do Jacuípe } \\
\text { Gavião }\end{array}$ \\
Não-CAT (controle) & Biritinga & .
\end{tabular}

A amostra final foi constituída de 228 alunos, 110 egressos da metodologia e 118 de escolas que não adotaram a metodologia (controle).

O instrumento de coleta foi um questionário, criado especificamente para aferir quatro dimensões pedagógicas diferentes e aplicado nos quatro municípios localizados nos Territórios do Sisal e da Bacia do Jacuípe. Ele foi produzido pela equipe de pesquisa a partir de outro, anteriormente produzido pela organização coordenadora, o Movimento de Organização Comunitária - MOC. A equipe ampliou o instrumento anterior e o adequou, dando a ele condições de aferir as variáveis em função das categorias empíricas definidas no projeto. O questionário compunha-se de 42 itens distribuídos em dois blocos: um para a coleta de informações que nos possibilitassem esboçar um perfil socioeconômico do sujeito pesquisado, com informações referentes à idade, renda familiar e escolaridade dos pais, por exemplo; o outro, com vistas à aferição das categorias construídas na pesquisa: Ativismo, Importância da Escola, Orientação Ideológica e Fixação no Território.

A aplicação do instrumento foi realizada por três pesquisadores e implicou oito viagens a campo, entre novembro de 2016 e fevereiro de 2017. Cada viagem foi planejada com o auxílio e a participação da organização executora (OE), que estabeleceu contato entre os pesquisadores e colaboradores em cada município (em geral, parceiros e atuantes na área de educação. Após os contatos iniciais, acordávamos com a OE e o colaborador a data da viagem, e seguíamos de carro pela zona rural dos municípios em busca de ex-alunos. Estes, encontramos nas escolas, em suas residências, nos espaços públicos, enfim, em locais variados. Após nos apresentarmos, buscávamos qualquer ambiente nas proximidades que fosse adequado para a aplicação do instrumento. O questionário era lido item por item, pausadamente, e explicávamos calma e repetidamente qualquer dúvida sobre as questões colocadas. A duração da aplicação variou entre 15 e 30 minutos.

Após a coleta, os dados foram inicialmente digitalizados em uma planilha e, posteriormente, lançados no aplicativo de análise estatística SPSS. As análises compreenderam a descrição, as associações e os testes estatísticos de significância. O 
conjunto de variáveis que mediram as categorias empíricas - Ativismo, Importância da Escola, Orientação Ideológica e Fixação no Território geraram medidas compostas - índices que possibilitaram comparar os grupos.

\section{RESULTADOS E DISCUSSÃO}

\section{Perfil dos Egressos}

Da amostra total de 228 ex-alunos entrevistados, 110 (48\%) foram do grupo de tratamento (CAT) e 118 (52\%), do grupo de controle. Desse mesmo total, 212 (93\%) exalunos residem na zona rural e apenas 16 alunos (7\%) residem na zona urbana dos municípios. Em relação à distribuição entre grupo de tratamento e controle por local de residência, respectivamente, 100 ex-alunos CAT (90,9\% desse grupo) ainda residem na zona rural, enquanto que 112 ex-alunos Não CAT (95,7\% desse grupo) ainda residem na zona rural. Quanto ao perfil dos egressos entrevistados, por idade, estes possuem, em média, 16 anos de idade, com o grupo CAT tendo, em média, 15 anos e 4 meses, e o grupo Não CAT tendo 16 anos de 8 meses. Os egressos Não CAT possuem, em média, 1 ano e 4 meses a mais.

Em relação a gênero, 93 (41\%) egressos são do sexo masculino e 135 (59\%) são do gênero feminino. A análise por grupos mostra que, no grupo CAT, 41 (37\%) egressos são do gênero masculino e 69 (63\%) femininos Para o grupo Não CAT, 52 (44\%) são do gênero masculino e 66 (56\%) feminino. A figura 1 apresenta a distribuição dos egressos por cor/raça e grupo CAT e Não CAT. É possível observar que os pardos somam 120 egressos e representam $52,6 \%$ do total, sendo, assim, o maior grupo por cor/raça.

Figura 1. Distribuição dos egressos por cor/raça

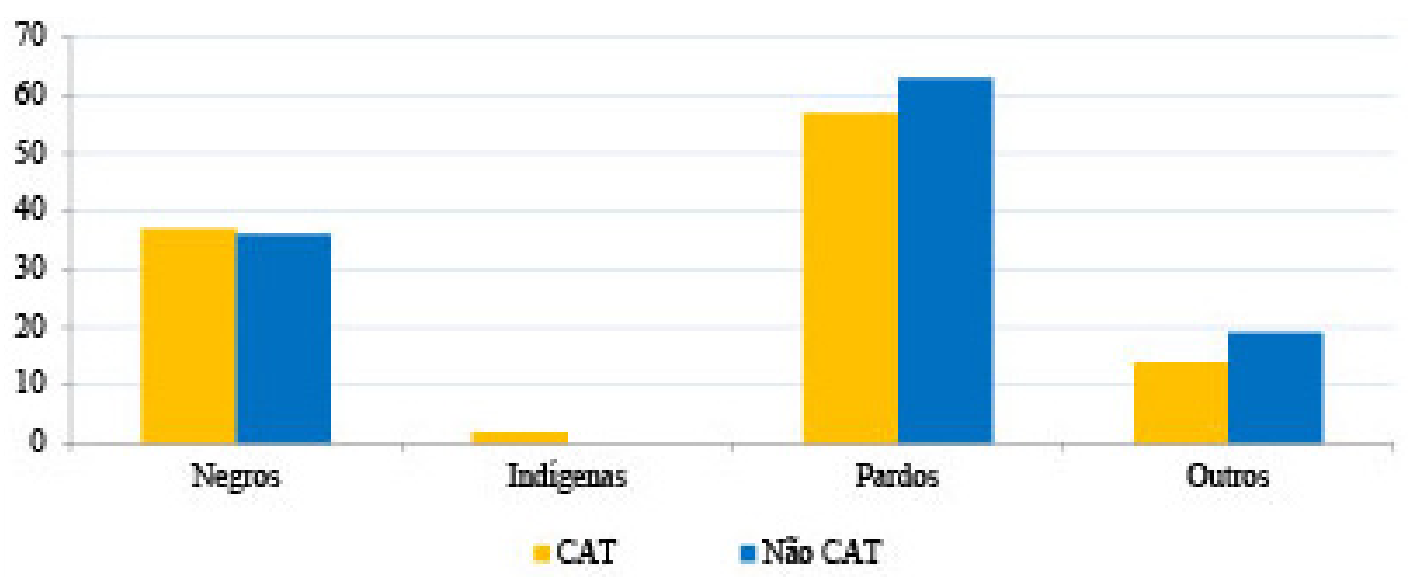

Fonte: Elaboração a partir de dados da pesquisa 
Desse total, 57 são do grupo CAT e 63 do grupo Não CAT, todos em torno de $50 \%$ dos egressos desses respectivos grupos. O segundo maior grupo é formado por negros, que, com 73 egressos, representam 32,0\% do total, distribuídos entre 37 no grupo CAT e 36 no grupo Não CAT. Quando aos demais, foram 2 indígenas e 33 no grupo outros, sendo que os dois indígenas estão no grupo CAT e o grupo outros distribuídos entre 14 para o grupo CAT e 19 para o grupo não CAT.

No que diz respeito à forma de organização original da turma, $36(15,7 \%)$ dos egressos, 26 CAT e 10 Não CAT, não vieram do regime multisseriado. Do total de 228 egressos, 180 $(79,6 \%)$ ainda estão estudando, sendo 93 do grupo CAT, $85,3 \%$ do respectivo grupo, e 87 do grupo Não CAT, 74,4\% do respectivo grupo. Este resultado é particularmente importante, uma vez que o percentual de egressos do grupo CAT que ainda está estudando é superior, em 10,9\%, o que sugere um maior aproveitamento dos recursos empregados na formação básica dos alunos.

A estrutura familiar pode ser analisada, inicialmente, pelo número de irmãos dos egressos. A média geral para todos os egressos foi de 3 irmãos, sendo que, para o grupo CAT, este número é de 3,16 irmãos em média, e para o grupo não CAT este número é de 2,79. Ou seja, o grupo CAT apresenta, em média, um número relativamente maior de membros da família.

Quanto ao nível de formação dos pais, a escolaridade do pai é, em média, de 2,1 anos e a da mãe é de 2,9 anos. Entre os grupos, o CAT apresenta o pai com 2,2 anos em média, e a mãe com 3,05 anos. Já o grupo não CAT, o pai possui 1,9 anos, em média, e a mãe 2,9 anos. Isso mostra que os pais do grupo CAT apresentam escolaridade mais elevada.

Em relação à renda familiar, apenas 128 (56\%) egressos, do total de 228, souberam informar um valor aproximado para esta variável. Estes estão distribuídos entre 54 para o grupo CAT e 74 para o grupo Não CAT. A renda média geral foi, para o ano de 2016, de R\$ 593,2 . O grupo CAT apresentou uma renda familiar média de $\mathrm{R} \$ 456$, 0 enquanto o grupo Não CAT uma renda familiar de $\mathrm{R} \$ 757,8$. Isso mostra que a renda familiar do grupo Não CAT é $66,2 \%$ maior que o grupo CAT.

Finalmente, em relação à renda dos egressos, só houve 34 respondentes, $14,5 \%$ do total, sendo 17 do grupo CAT e 17 do grupo Não CAT. Desse modo, essa variável é muito pouco confiável para ser utilizada nos testes estatísticos a serem aplicadas na próxima seção. Para 
esses 34 respondentes, a renda média aferida foi de $\mathrm{R} \$ 534,0$. O grupo CAT teve renda média de $\mathrm{R} \$ 396,9$ e o Não CAT renda de $\mathrm{R} \$ 671$, 0 . Desse modo, o grupo Não CAT apresenta renda $69,0 \%$ maior que o grupo CAT. O que pode ser justificado pelo maior idade mais elevada do grupo Não CAT.

As diferenças observadas entre os dois grupos para essas variáveis socioeconômicas apontam para a necessidade de controle para as estimativas econométricas e a mensuração dos efeitos do programa. Os resultados destas análises serão apresentados a seguir.

\section{EFEITOS DO PROGRAMA: ATIVISMO, IMPORTÂNCIA DA ESCOLA, ORIENTAÇÃO IDEOLÓGICA E FIXAÇÃO NO TERRITÓRIO}

\section{Efeitos gerais}

Os resultados para o efeito do programa CAT sobre ativismo social, a importância atribuída ao papel da escola e o efeito para a formação de opinião do indivíduo (orientação ideológica) foram controlados pelas variáveis descritas anteriormente. O procedimento aplicado foi o de regressões multivariadas de equações lineares, utilizando o método de Mínimos Quadrados Ordinários. As equações abaixo mostram como o efeito do Programa CAT foi aferido sobre as variáveis de Ativismo Social (Ativismo), Importância da Escola (Imp_ escol) e Fixação no Território (Fix_Territ). Desse modo foram estimados três conjuntos de modelos, a saber:

$$
\begin{aligned}
& \text { Ativismo }=b_{0}+\gamma C A T+b_{1} i d a d e+b_{2} g e ̂ n e r o+b_{3} c o r+b_{4} \text { nirmos }+b_{5} \text { escolpais }+b_{6 r e n d a f}+u \\
& \text { Imp_escol }=b_{0}+\gamma C A T+b_{1} i d a d e+b_{2} \text { ênero }+b_{3} c o r+b_{4} \text { nirmos }+b_{5} \text { escolpais }+b_{6 r e n d a f}+u \\
& \text { Fix_Territ }=b_{0}+\gamma C A T+b_{1} \text { idade }+b_{2} \text { gênero }+b_{3} c o r+b_{4} \text { nirmos }+b_{5} \text { escolpais }+b_{6 r e n d a f}+u
\end{aligned}
$$

Nas equações, as variáveis de interesse são explicadas pela variável de participação no programa (CAT) e características dos egressos e da respectiva família, a saber: idade, gênero, cor, número de irmãos (nirmos), escolaridade dos pais (escolpais) e renda familiar (rendaf). O parâmetro $y$ permitirá a mensuração do efeito do programa CAT sobre as três variáveis de interesse da pesquisa. A variável CAT é binária, sendo 1 se o egresso participou (grupo de tratamento) do programa e o caso contrário (grupo de controle). 


\section{Construção de medidas compostas:}

Para a realização dos testes, foram selecionadas, principalmente, as variáveis do questionário referentes a ativismo social (cinco itens), importância da escola para o egresso (oito itens), variáveis de orientação ideológica dos egressos (sete itens) e uma variável de fixação no território. Para tanto, foram gerados índices referentes ao valor médio que o egresso atribuiu a cada item do respectivo bloco: Índice de Ativismo Social, Índice de Importância da Escola, Índice Orientação Ideológica e um medida simples para a variável Fixação no Território, descritos a seguir:

- Índice de Ativismo Social. Com pesos de importância crescente, de o a 5, os egressos foram questionados sobre a importância do programa para o ativismo social em: atividades escolares; sindicais; associativas; artísticas, religiosas. O índice refere-se à média dos valores atribuídos a cada variável.

- Índice de Importância da Escola. Com pesos de importância crescente, de o a 5, os egressos foram questionados sobre a importância do programa para: formação de hábitos de leitura; participação em manifestações por direitos; participação em algum coletivo político; participação em grupos de teatro, música, dança, capoeira, outros; construção de hortas domésticas; manutenção de práticas de destinação do lixo doméstico; participação em manifestações em defesa do meio ambiente; realização de tarefas da casa. O índice refere-se à média dos valores atribuídos a cada variável.

- Índice Orientação Ideológica: Com pesos de importância crescente, de -1 (contra), o (indiferente) e 1 (favorável) os egressos foram questionados sobre a importância do programa para: casamento entre pessoas do mesmo sexo; adoção de crianças por casais homossexuais; descriminalização das drogas; pena de morte para certos tipos de crime; maioridade penal aos 16 anos; fazer queimadas para plantar e renovar os pastos; reservas de vagas em concursos públicos e na universidade para os negros. $\mathrm{O}$ índice refere-se à média dos valores atribuídos a cada variável. Mas cabe ressaltar que, para os questionamentos sobre pena de morte para certos tipos de crime, maioridade penal aos 16 anos e realização e queimadas para plantar e renovar os pastos a atribuição de valores -1 (contra), 1 (favorável) foi invertida. Para evitar ambiguidades na interpretação, cabe lembrar que o índice não mede o "liberalismo" ou o "conservadorismo" dos sujeitos, tampouco de seus discursos. O índice visa representar 
o grau de associação de cada grupo a um dos polos ideológicos, através de uma relação entre o número de respostas contabilizadas e atribuíveis a um dos polos (de valor +1 ou -1 ) e o número de respostas possíveis para o grupo considerado, ou seja, 21 (3 opções possíveis em 7 questões para cada egresso do grupo analisado).

- FixaçãonoTerritório: Diferentemente dastrêsmedidas compostas (índices) anteriores, a contribuição da metodologia na fixação do egresso no território foi aferida por uma única variável, com as seguintes categorias: na zona rural do mesmo município e com a agricultura; na região semiárida do mesmo município, mas na cidade e com outra atividade diferente da agricultura; em uma grande cidade; em outra região. Para conferir a coerência com a concepção do projeto, demos um tratamento estatístico de variável com escala ordinal, atribuindo maior valor à primeira categoria.

Começamos por apresentar uma síntese dos resultados das análises na tabela abaixo, onde constam os valores médios dos grupos CAT e Não CAT e respectivas diferenças e estatísticas de testes. É possível observar que os índices dos egressos do grupo CAT são superiores em relação ao grupo Não CAT. No entanto, apenas os índices de Ativismo Social e Importância da Escola apresentam diferenças de média estatisticamente significante. Nas regressões apresentadas nas tabelas a seguir, serão analisados os efeitos causais do CAT sobre esses índices, controlando pelas características dos egressos e da respectiva família, de maneira que a variável CAT, introduzida nas regressões, já expressará a diferença de média do CAT em relação ao Não CAT e respectiva significância.

Tabela 2 - Médias e testes diferenças de médias dos índices, para os grupos CAT e Não CAT

\begin{tabular}{llllll}
\hline Índice & $\begin{array}{l}\text { Média } \\
\text { CAT }\end{array}$ & $\begin{array}{l}\text { Média } \\
\text { Não CAT }\end{array}$ & Diferença & $\begin{array}{l}\text { Teste }(t) \\
\text { Ho: dif }=0\end{array}$ & $\begin{array}{l}\text { Valor } P \\
\operatorname{Pr}(|T|>|t|)\end{array}$ \\
\hline Ativismo Social & 1,980 & 1,691 & 0,288 & 3,872 & 0,000 \\
$\begin{array}{l}\text { Importância da } \\
\text { Escola }\end{array}$ & 2,643 & 2,022 & 0,620 & 7,490 & 0,000 \\
$\begin{array}{l}\text { Orientação } \\
\text { Ideológica }\end{array}$ & 0,160 & 0,104 & 0,056 & 1,195 & 0,233 \\
$\begin{array}{l}\text { Fixação no } \\
\text { Território }\end{array}$ & 2,980 & 2,868 & 0,112 & 0,948 & 0,344 \\
\hline
\end{tabular}

Fonte: Elaboração própria, com base em estatísticas dos dados da pesquisa.

Os resultados a seguir tratam dos efeitos gerais do CAT para as categorias "Ativismo Social", Importância da Escola" e "Fixação no Território"; a análise da categoria "Orientação 
Ideológica" será apresentada mais à frente. Estes efeitos estão expressos na Tabela 3, onde os valores indicam a diferença entre as médias CAT e não-CAT (as regressões simples equivalem, econometricamente, ao teste de diferença de médias simples). Percebe-se, na linha 3, que, com exceção da variável de fixação no território, que esta diferença foi positiva, para o CAT, para todas as demais categorias, adicionando as variáveis de controle (colunas numeradas pares) ou não (colunas ímpares). Os resultados por categoria são descritos logo após a tabela.

Tabela 3 - Regressões simples e multivariadas do efeito do CAT.

\begin{tabular}{|c|c|c|c|c|c|c|}
\hline & $\begin{array}{l}\text { (1) } \\
\text { Ativismo }\end{array}$ & $\begin{array}{l}\text { (2) } \\
\text { Ativismo }\end{array}$ & $\begin{array}{l}\text { (3) } \\
\text { Imp_Escol }\end{array}$ & $\begin{array}{l}\text { (4) } \\
\text { Imp_Escol }\end{array}$ & $\begin{array}{l}\text { (5) } \\
\text { FixTer }\end{array}$ & $\begin{array}{l}(6) \\
\text { FixTer }\end{array}$ \\
\hline Cat & $\begin{array}{l}0.289^{* * *} \\
(3.87)\end{array}$ & $\begin{array}{l}0.257^{* *} \\
(2.63)\end{array}$ & $\begin{array}{l}0.621^{* * *} \\
(7.49)\end{array}$ & $\begin{array}{l}0.601^{* * *} \\
(5.31)\end{array}$ & $\begin{array}{l}0.197 \\
(1.67)\end{array}$ & $\begin{array}{l}0.275 \\
(1.74)\end{array}$ \\
\hline Idade & & $\begin{array}{l}-0.0103 \\
(-1.32)\end{array}$ & & $\begin{array}{l}-0.00758 \\
(-0.84)\end{array}$ & & $\begin{array}{l}-0.0513^{* * *} \\
(-4.07)\end{array}$ \\
\hline Gener & & $\begin{array}{l}-0.267^{* *} \\
(-2.75)\end{array}$ & & $\begin{array}{l}0.0489 \\
(0.43)\end{array}$ & & $\begin{array}{l}-0.00288 \\
(-0.02)\end{array}$ \\
\hline Negro & & $\begin{array}{l}0.122 \\
(1.18)\end{array}$ & & $\begin{array}{l}0.132 \\
(1.10)\end{array}$ & & $\begin{array}{l}-0.327 \\
(-1.94)\end{array}$ \\
\hline Irmao & & $\begin{array}{l}-0.0330 \\
(-1.57)\end{array}$ & & $\begin{array}{l}-0.0107 \\
(-0.44)\end{array}$ & & $\begin{array}{l}-0.000111 \\
(-0.00)\end{array}$ \\
\hline escol_pais & & $\begin{array}{l}0.0484 \\
(1.82)\end{array}$ & & $\begin{array}{l}0.0485 \\
(1.58)\end{array}$ & & $\begin{array}{l}-0.0117 \\
(-0.27)\end{array}$ \\
\hline Renda & & $\begin{array}{l}0.000261^{*} \\
(2.22)\end{array}$ & & $\begin{array}{l}0.0000628 \\
(0.46)\end{array}$ & & $\begin{array}{l}0.0000353 \\
(0.19)\end{array}$ \\
\hline _cons & $\begin{array}{l}1.691^{* * *} \\
(32.52)\end{array}$ & $\begin{array}{l}1.671^{* * *} \\
(8.34)\end{array}$ & $\begin{array}{l}2.022^{* * *} \\
(35.14)\end{array}$ & $\begin{array}{l}1.986^{* * *} \\
(8.56)\end{array}$ & $\begin{array}{l}1.982^{* * *} \\
(24.11)\end{array}$ & $\begin{array}{l}2.983^{* * *} \\
(8.91)\end{array}$ \\
\hline$N$ & 227 & 129 & 228 & 129 & 218 & 127 \\
\hline
\end{tabular}

$t$ statistics in parentheses. ${ }^{*} p<0.05,{ }^{* *} p<0.01,{ }^{* * *} p<0.001$.

Fonte: Os autores.

Inicialmente, é possível observar, na regressão (1), que o CAT apresenta um efeito positivo e estatisticamente significante sobre Ativismo Social, que, numa escala que pode ir de 1 a 5, este é o,29 maior que o não CAT. Na regressão (2), é possível observar que, apenas ao adicionar as variáveis de controle o valor do coeficiente, diminui para 0,257; no entanto, a redução é pequena, o que garante a robustez dos resultados. Das variáveis de controle introduzidas, apenas gênero e renda familiar apresentaram-se estatisticamente significantes.

Em relação à importância que o egresso atribui à escola, nota-se que, numa escala que também vai de 1 a 5, as regressões (3) mostram que o CAT tem um efeito estatisticamente 
significante e positivo de fazer com que o aluno valorize o papel da escola no desempenho de suas atividades em 0,621. Este resultado se mantém na equação (4), após o controle pelas características, com uma pequena redução do valor do parâmetro para o,601. Embora as variáveis de controle tenham contribuído para reduzir o efeito do CAT, nenhuma destas apresentou parâmetro estatisticamente significante.

Uma importante contribuição do projeto CAT seria o estímulo à permanência do egresso no campo para o convívio com o semiárido. Verificamos se o CAT teria influência maior na fixação do egresso no campo ou na escolha dele em se deslocar para outros espaços para construir o seu futuro.

O efeito da metodologia sobre o local onde o egresso pretende estruturar sua vida pode ser vista nas colunas (5) e (6); como se observa, não houve efeito sobre essa categoria. O único resultado relevante é o fato de que, quanto maior a idade do egresso, menor a propensão deste a sair do campo, uma vez que, quanto maior o valor da variável "Fixação no Território", maior o efeito do CAT na escolha de sair do campo. A tabela 2 apresenta os resultados das regressões econométricas simples e multivariadas referentes ao efeito do CAT sobre as categorias.

Apresentados os efeitos gerais das categorias anteriores, pode-se decompor "Orientação Ideológica". Para analisá-la, foi construído um índice baseado no levantamento da opinião dos ex-alunos em relação aos seguintes temas: (i) Casamento entre pessoas do mesmo sexo; (ii) Adoção de crianças por casais homossexuais; (iii) Descriminalização das drogas; (iv) Pena de morte para certos tipos de crime; (v) Maioridade penal aos 16 anos; (vi) Fazer queimadas para plantar e renovar os pastos; e (vii) Reservas de vagas em concursos públicos e na universidade para os negros. A aferição das opiniões foi feita com base nas seguintes opiniões: (a) Favoráveis $=1 ;$ (b) Contra $=-1$; Indiferentes $=0$, com exceção dos temas iv, v e vi, que tiveram seus valores invertidos. Como apresentado na tabela 2, o valor médio do índice de formação ideológica foi de 0,13 - para os egressos CAT foi de 0,16, enquanto que, para os egressos Não-CAT, este foi de 0,10. Isso revela que, em média, há uma tendência ligeiramente superior de egressos CAT se verem representados em um discurso liberal (considerando o sentido político do termo, e não o econômico), em comparação aos Não-CAT. A tabela 4 apresenta o efeito do CAT sobre a orientação ideológica dos ex-alunos. É possível observar que o fato de ser egresso CAT não tem efeito estatisticamente significante sobre a formação ideológica dos egressos presentes na amostra, e o único resultado a destacar é 
o efeito positivo estatisticamente significante de gênero na formação ideológica, indicando que as mulheres da amostra tendem mais a um discurso liberal.

Tabela 4 - Resultados da regressão sobre o efeito do CAT na formação ideológica dos egressos

\begin{tabular}{cl}
\hline & Formação ideológica \\
\hline Cat & -0.0412 \\
& $(-0.64)$ \\
Idade & -0.00334 \\
& $(-0.65)$ \\
Gênero & $-0.153^{*}$ \\
& $(-2.39)$ \\
Negro & -0.0600 \\
& $(-0.88)$ \\
Irmãos & -0.0138 \\
& $(-0.99)$ \\
escol_pais & 0.0243 \\
& $(1.39)$ \\
Renda & -0.000143 \\
& $(-1.84)$ \\
_cons & $0.406^{* *}$ \\
Fonte: Os autores. & $(3.06)$ \\
N & 129 \\
\hline tstatistics in parentheses. $p<0.05,^{* *} p<0.01{ }^{* * *} p<0.001$ \\
\end{tabular}

Esses resultados apresentam uma primeira visão, panorâmica, dos impactos da execução do projeto CAT comparados à atuação da escola regular. A categoria "Ativismo Social" assinala ganhos positivos na execução do projeto, demonstrando que ex-alunos CAT têm propensão a participar mais da vida comunitária. A "Importância da Escola" também aponta ganhos positivos associados à execução do CAT, um indício de que seus egressos traduzem as experiências de sala de aula em novos comportamentos com mais frequência.

A análise preliminar da categoria "Orientação Ideológica", por sua vez, não apresentou ganhos significativos associados ao projeto. Este resultado, além de reforçar uma literatura existente sobre os limites do potencial da escola na formação moral do sujeito (ROSA, 2001), sugerem prudência na interpretação dos resultados positivos da categoria "Ativismo Social", já que a maior participação dos egressos CAT na vida comunitária pode se realizar sob conteúdo ideológico que reforce a reprodução social.

A ausência de efeito do projeto em motivar os egressos a permanecer no Semiárido pode serverificada na categoria "Fixação no Território". Contudo, levando-se em consideração a ausência de formação superior pública nos municípios da amostra e a percepção positiva da 
escola entre os egressos CAT, pode-se aventar uma relação entre continuidade dos estudos e desejo de sair do Semiárido, algo ainda a ser estudado.

\section{Efeitos por variável}

Quando o ativismo social é decomposto por itens, é possível estimar os cinco modelos correspondentes a cada um dos itens da medida composta e com variáveis de controle. Esta decomposição resultou na estimação de 10 modelos. Observa-se que as atividades que apresentaram efeitos estatisticamente significantes foram atividades escolar, nas colunas (1) e (2), atividade artística (coluna 7), mas que não se mantiveram após a introdução de variáveis de controle na coluna (8), e atividade religiosa (coluna 9) e que se manteve após a introdução de variáveis de controle na coluna (10).

Tabela 5 - Regressões simples e multivariadas do efeito do CAT sobre ativismo social

\begin{tabular}{|c|c|c|c|c|c|c|c|c|c|c|}
\hline & $\begin{array}{l}\text { (1) } \\
\text { Ativismo1 }\end{array}$ & $\begin{array}{l}\text { (2) } \\
\text { Ativismo1 }\end{array}$ & $\begin{array}{l}\text { (3) } \\
\text { Ativismoz }\end{array}$ & $\begin{array}{l}\text { (4) } \\
\text { Ativismoz }\end{array}$ & $\begin{array}{l}\text { (5) } \\
\text { Ativismoz }\end{array}$ & $\begin{array}{l}(6) \\
\text { Ativismoz }\end{array}$ & $\begin{array}{l}\text { (7) } \\
\text { Ativismo }\end{array}$ & $\begin{array}{l}\text { (8) } \\
\text { Ativismos }\end{array}$ & $\begin{array}{l}\text { (9) } \\
\text { Ativismos }\end{array}$ & $\begin{array}{l}\text { (10) } \\
\text { Ativismo5 }\end{array}$ \\
\hline Cat & $\begin{array}{l}0.484^{* *} \\
(3.17)\end{array}$ & $\begin{array}{l}0.471^{*} \\
(2.32)\end{array}$ & $\begin{array}{l}-0.101 \\
(-1.23)\end{array}$ & $\begin{array}{l}0.0216 \\
(0.19)\end{array}$ & $\begin{array}{l}-0.0278 \\
(-0.30)\end{array}$ & $\begin{array}{l}0.00000 \\
(0.00)\end{array}$ & $\begin{array}{l}0.325^{*} \\
(1.98)\end{array}$ & $\begin{array}{l}0.113 \\
(0.53)\end{array}$ & $\begin{array}{l}0.546^{* * *} \\
(4.08)\end{array}$ & $\begin{array}{l}0.479^{* *} \\
(3.01)\end{array}$ \\
\hline Idade & & $\begin{array}{l}-0.0389^{*} \\
(-2.04)\end{array}$ & & $\begin{array}{l}0.0159 \\
(1.77)\end{array}$ & & $\begin{array}{l}0.0214 \\
(1.82)\end{array}$ & & $\begin{array}{l}-0.0370^{*} \\
(-2.21)\end{array}$ & & $\begin{array}{l}-0.00996 \\
(-0.79)\end{array}$ \\
\hline Genero & & $\begin{array}{l}-0.235 \\
(-1.17)\end{array}$ & & $\begin{array}{l}-0.189 \\
(-1.68)\end{array}$ & & $\begin{array}{l}-0.0309 \\
(-0.21)\end{array}$ & & $\begin{array}{l}-0.216 \\
(-1.03)\end{array}$ & & $\begin{array}{l}-0.605^{* * *} \\
(-3.83)\end{array}$ \\
\hline Negro & & $\begin{array}{l}-0.0402 \\
(-0.19)\end{array}$ & & $\begin{array}{l}-0.158 \\
(-1.31)\end{array}$ & & $\begin{array}{l}0.104 \\
(0.66)\end{array}$ & & $\begin{array}{l}0.601^{* *} \\
(2.69)\end{array}$ & & $\begin{array}{l}-0.0276 \\
(-0.16)\end{array}$ \\
\hline Irmaos & & $\begin{array}{l}-0.0395 \\
(-0.86)\end{array}$ & & $\begin{array}{l}-0.0189 \\
(-0.78)\end{array}$ & & $\begin{array}{l}-0.0389 \\
(-1.22)\end{array}$ & & $\begin{array}{l}-0.00158 \\
(-0.03)\end{array}$ & & $\begin{array}{l}-0.0680^{*} \\
(-1.99)\end{array}$ \\
\hline $\begin{array}{l}\text { escol_ } \\
\text { pais }\end{array}$ & & $\begin{array}{l}0.0171 \\
(0.31)\end{array}$ & & $\begin{array}{l}0.00801 \\
(0.25)\end{array}$ & & $\begin{array}{l}0.0550 \\
(1.33)\end{array}$ & & $\begin{array}{l}0.107 \\
(1.82)\end{array}$ & & $\begin{array}{l}0.0475 \\
(1.10)\end{array}$ \\
\hline Renda & & $\begin{array}{l}0.00037 \\
(1.34)\end{array}$ & & $\begin{array}{l}0.0004^{* *} \\
(2.96)\end{array}$ & & $\begin{array}{l}0.0005^{* *} \\
(3.16)\end{array}$ & & $\begin{array}{l}-0.00006 \\
(-0.25)\end{array}$ & & $\begin{array}{l}0.00013 \\
(0.70)\end{array}$ \\
\hline _cons & $\begin{array}{l}2.173^{* * *} \\
(20.06)\end{array}$ & $\begin{array}{l}2.727^{* * *} \\
(6.44)\end{array}$ & $\begin{array}{l}1.263^{* * *} \\
(22.16)\end{array}$ & $\begin{array}{l}0.768^{* *} \\
(3.32)\end{array}$ & $\begin{array}{l}1.345^{* * *} \\
(20.75)\end{array}$ & $\begin{array}{l}0.465 \\
(1.53)\end{array}$ & $\begin{array}{l}1.779^{* * *} \\
(15.54)\end{array}$ & $\begin{array}{l}2.095^{* * *} \\
(4.86)\end{array}$ & $\begin{array}{l}1.931^{* * *} \\
(20.72)\end{array}$ & $\begin{array}{l}2.302^{* * *} \\
(7.07)\end{array}$ \\
\hline$N$ & 209 & 117 & 219 & 127 & 217 & 126 & 219 & 127 & 225 & 129 \\
\hline
\end{tabular}

Alocalização dos efeitosestatisticamente significantes nas variáveis "atividadeescolar" e "atividade religiosa" torna necessário que tenhamos mais prudência no apontamento de efeitos positivos do projeto na categoria "Ativismo Social", já que se trata de instituições reconhecidamente de forte cunho reprodutivista. A falta de efeito positivo estatisticamente significante na categoria "Orientação Ideológica" reforça este apelo pela ponderação, que 
pode, no entanto, ser desmentido por análises em sítio do conteúdo ideológico das escolas e instituições religiosas frequentadas pelos egressos.

A tabela 6 apresenta o efeito do CAT sobre o papel atribuído à escola na vida do indivíduo e se este se mantém após a introdução das variáveis de controle. Os efeitos que se mantiveram foram: manifestações por direitos (linhas 3 e 4); participação em grupos culturais - teatro, dança, etc, (linhas 7 e 8); hortas domésticas (linhas g e 10); manifestações em defesa do meio ambiente, (linhas 13 e 14); e realização das tarefas de casa (linhas 15 e 16).

Tabela 6 - Efeito do CAT sobre o papel atribuído à escola pelo egresso.

\begin{tabular}{|c|c|c|c|c|c|c|c|c|c|}
\hline & Cat & Idade & Genero & Negro & Irmaos & escol_pais & Renda & _cons & $\mathbf{N}$ \\
\hline $\begin{array}{l}\text { (1) Contr/ } \\
\text { Esc1 }\end{array}$ & $\begin{array}{l}0.669^{* * *} \\
(3.73)\end{array}$ & & & & & & & $\begin{array}{l}2.695^{* * *} \\
(21.62)\end{array}$ & 228 \\
\hline $\begin{array}{l}\text { (2) Contr/ } \\
\text { Esc1 }\end{array}$ & $\begin{array}{l}0.517^{* *} \\
(3.30)\end{array}$ & $\begin{array}{l}0.00391 \\
(0.19)\end{array}$ & $\begin{array}{l}-0.381 \\
(-1.50) \\
\end{array}$ & $\begin{array}{l}0.306 \\
(1.13)\end{array}$ & $\begin{array}{l}-0.0122 \\
(-0.22)\end{array}$ & $\begin{array}{l}0.0881 \\
(1.27)\end{array}$ & $\begin{array}{l}0.000691^{*} \\
(2.25)\end{array}$ & $\begin{array}{l}2.102^{* * *} \\
(4.03)\end{array}$ & 129 \\
\hline $\begin{array}{l}\text { (3) Contr/ } \\
\text { Esc2 }\end{array}$ & $\begin{array}{l}0.817^{* * *} \\
(5.22)\end{array}$ & & & & & & & $\begin{array}{l}1.365^{* * *} \\
(12.48)\end{array}$ & 225 \\
\hline $\begin{array}{l}\text { (4) Contr/ } \\
\text { Esc2 }\end{array}$ & $\begin{array}{l}0.941^{* * *} \\
(4.24)\end{array}$ & $\begin{array}{l}-0.00972 \\
(-0.55)\end{array}$ & $\begin{array}{l}-0.0410 \\
(-0.19)\end{array}$ & $\begin{array}{l}0.249 \\
(1.06) \\
\end{array}$ & $\begin{array}{l}-0.0886 \\
(-1.85)\end{array}$ & $\begin{array}{l}0.0613 \\
(1.02)\end{array}$ & $\begin{array}{l}-0.000113 \\
(-0.42)\end{array}$ & $\begin{array}{l}1.663^{* * *} \\
(3.66)\end{array}$ & 129 \\
\hline $\begin{array}{l}\text { (5) Contr/ } \\
\text { Esc3 }\end{array}$ & $\begin{array}{l}0.132 \\
(1.71)\end{array}$ & & & & & & & $\begin{array}{l}1.088^{* * *} \\
(20.09)\end{array}$ & 223 \\
\hline $\begin{array}{l}\text { (6) Contr/ } \\
\text { Esc3 }\end{array}$ & $\begin{array}{l}0.172 \\
(1.42)\end{array}$ & $\begin{array}{l}0.0240^{*} \\
(2.50)\end{array}$ & $\begin{array}{l}0.302^{*} \\
(2.51)\end{array}$ & $\begin{array}{l}0.216 \\
(1.68)\end{array}$ & $\begin{array}{l}0.0250 \\
(0.96)\end{array}$ & $\begin{array}{l}0.0413 \\
(1.25) \\
\end{array}$ & $\begin{array}{l}0.0000865 \\
(0.60)\end{array}$ & $\begin{array}{l}0.245 \\
(0.99)\end{array}$ & 127 \\
\hline $\begin{array}{l}\text { (7) Contr/ } \\
\text { Esc4 }\end{array}$ & $\begin{array}{l}0.517^{* *} \\
(3.30)\end{array}$ & & & & & & & $\begin{array}{l}1.456^{* * *} \\
(13.26)\end{array}$ & 224 \\
\hline $\begin{array}{l}\text { (8) Contr/ } \\
\text { Esc4 }\end{array}$ & $\begin{array}{l}0.576^{*} \\
(2.49)\end{array}$ & $\begin{array}{l}-0.0204 \\
(-1.11)\end{array}$ & $\begin{array}{l}0.0506 \\
(0.22)\end{array}$ & $\begin{array}{l}0.163 \\
(0.66)\end{array}$ & $\begin{array}{l}0.0475 \\
(0.95) \\
\end{array}$ & $\begin{array}{l}0.0253 \\
(0.40)\end{array}$ & $\begin{array}{l}0.0000697 \\
(0.25)\end{array}$ & $\begin{array}{l}1.544^{\text {** }} \\
(3.25)\end{array}$ & 129 \\
\hline $\begin{array}{l}\text { (9) Contr/ } \\
\text { Esc5 }\end{array}$ & $\begin{array}{l}0.854^{* * *} \\
(4.54)\end{array}$ & & & & & & & $\begin{array}{l}2.009^{* * *} \\
(15.27)\end{array}$ & 223 \\
\hline $\begin{array}{l}\text { (10) Contr/ } \\
\text { EsC5 }\end{array}$ & $\begin{array}{l}0.644^{*} \\
(2.34)\end{array}$ & $\begin{array}{l}0.00124 \\
(0.06)\end{array}$ & $\begin{array}{l}0.326 \\
(1.19)\end{array}$ & $\begin{array}{l}-0.145 \\
(-0.50)\end{array}$ & $\begin{array}{l}-0.0196 \\
(-0.33)\end{array}$ & $\begin{array}{l}0.0847 \\
(1.14)\end{array}$ & $\begin{array}{l}-0.000188 \\
(-0.57)\end{array}$ & $\begin{array}{l}2.024^{* * *} \\
(3.60)\end{array}$ & 128 \\
\hline $\begin{array}{l}\text { (11) Contr/ } \\
\text { Esc6 }\end{array}$ & $\begin{array}{l}0.607^{* *} \\
(3.03)\end{array}$ & & & & & & & $\begin{array}{l}2.643^{* * *} \\
(18.81)\end{array}$ & 220 \\
\hline $\begin{array}{l}\text { (12) Contr/ } \\
\text { Esc6 }\end{array}$ & $\begin{array}{l}0.485 \\
(1.66) \\
\end{array}$ & $\begin{array}{l}-0.0106 \\
(-0.46)\end{array}$ & $\begin{array}{l}0.402 \\
(1.39)\end{array}$ & $\begin{array}{l}0.253 \\
(0.82)\end{array}$ & $\begin{array}{l}0.00241 \\
(0.04)\end{array}$ & $\begin{array}{l}0.0499 \\
(0.63)\end{array}$ & $\begin{array}{l}-0.0000863 \\
(-0.25)\end{array}$ & $\begin{array}{l}2.540^{* * *} \\
(4.29)\end{array}$ & 126 \\
\hline $\begin{array}{l}\text { (13) Contr/ } \\
\text { Esc7 }\end{array}$ & $\begin{array}{l}0.848^{* * *} \\
(4.52)\end{array}$ & & & & & & & $\begin{array}{l}2.161^{* * *} \\
(16.39)\end{array}$ & 221 \\
\hline $\begin{array}{l}\text { (14) Contr/ } \\
\text { Esc7 }\end{array}$ & $\begin{array}{l}1.067^{* * *} \\
(4.09)\end{array}$ & $\begin{array}{l}-0.0404 \\
(-1.95)\end{array}$ & $\begin{array}{l}-0.146 \\
(-0.56) \\
\end{array}$ & $\begin{array}{l}-0.0858 \\
(-0.31)\end{array}$ & $\begin{array}{l}0.00847 \\
(0.15)\end{array}$ & $\begin{array}{l}0.0117 \\
(0.17)\end{array}$ & $\begin{array}{l}0.000347 \\
(1.10)\end{array}$ & $\begin{array}{l}2.747^{* * *} \\
(5.14)\end{array}$ & 129 \\
\hline $\begin{array}{l}\text { (15) Contr/ } \\
\text { Esc8 }\end{array}$ & $\begin{array}{l}0.656^{* * *} \\
(3.73)\end{array}$ & & & & & & & $\begin{array}{l}2.635^{* * *} \\
(21.44)\end{array}$ & 225 \\
\hline $\begin{array}{l}\text { (16) Contr/ } \\
\text { Esc8 }\end{array}$ & $\begin{array}{l}0.550^{*} \\
(2.27)\end{array}$ & $\begin{array}{l}-0.00770 \\
(-0.40)\end{array}$ & $\begin{array}{l}-0.0370 \\
(-0.15)\end{array}$ & $\begin{array}{l}0.120 \\
(0.47)\end{array}$ & $\begin{array}{l}-0.0581 \\
(-1.12)\end{array}$ & $\begin{array}{l}0.0311 \\
(0.48)\end{array}$ & $\begin{array}{l}-0.000342 \\
(-1.18)\end{array}$ & $\begin{array}{l}3.037^{* * *} \\
(6.14)\end{array}$ & 128 \\
\hline
\end{tabular}

t statistics in parentheses. ${ }^{*} p<0.05,{ }^{* *} p<0.01,{ }^{* * *} p<0.001$

Fonte: Os autores. 
Ao decompormos os efeitos positivos na categoria "Importância da Escola", verificamos, de pronto, um conjunto de variáveis que atestam ganhos do projeto. De fato, a análise demonstra que os egressos CAT mantêm, com mais frequência, algumas práticas sociais que apontam para um horizonte de mudança social, seja na participação de atos coletivos com esta finalidade explícita (como as manifestações políticas), seja pelo exercício de práticas artísticas, que estimulam o sujeito e sua comunidade a outro trato com as linguagens, por exemplo. Ateste-se, também, que o controle por gênero sustentou-se para "realização das tarefas domésticas", um pequeno indício de uma divisão do trabalho doméstico mais flexível entre egressos CAT. Em todos esses casos, os resultados sugerem maior agência dos egressos CAT, o que é reforçado pela relação explicitada no enunciado entre as variáveis e o primeiro ciclo de escolarização (vide enunciado da questão no anexo).

Os resultados aferidos para a categoria "Orientação Ideológica", decompostos por itens, demonstram similaridades na orientação ideológica entre os grupos Cat e Não-Cat (como pode ser visto na distribuição de frequências da tabela 7). Ao se considerar apenas os resultados de "Favoráveis" e "Contrários" em cada questão, percebe-se que ambos os grupos mantêm a mesma preferência - à exceção da opinião sobre IV, e, mesmo nesta, com baixos percentuais de diferença. Por outro lado, em 5 das 7 questões, a percentagem de egressos CAT que se vinculam ao polo conservador (vide construção do índice de orientação ideológica, página 13) é menor que os não CAT (as exceções são as questões IV e V, que tratam mais especificamente de pautas do debate de segurança pública). Sobre os dados dos "Sem Opinião", estes são mais numerosos no grupo CAT para todos os casos, à exceção da questão VII. Conjuntamente, esses dados indicam que as maiorias tendem a seguir o mesmo padrão de resposta em ambos os grupos; contudo, a percentagem de egressos CAT cujas opiniões se associam ao polo conservador tende a ser menor, sendo equilibrado por uma maior presença dos "Sem opinião".

Uma última observação sobre a tabela acima diz respeito às respostas do grupo não-CAT referentes à diversidade de gênero (questões I e II). A distribuição de frequências demonstra que parte substancial dos egressos do grupo é contrária ao casamento entre pessoas do mesmo sexo, mas favorável à adoção de crianças por casais homossexuais. A aparente incoerência entre as duas respostas, que pode intrigar o leitor, foi detectada durante a coleta pelos aplicadores do questionário, que esclareceram as questões e as repetiram quantas vezes necessário a fim de garantir a fidedignidade dos dados. 
Tabela 7 - Cruzamento das variáveis que compõem a categoria orientação ideológica entre egressos CAT e Não CAT (em números percentuais)

\begin{tabular}{|c|c|c|c|c|c|c|c|c|}
\hline & \multicolumn{3}{|l|}{ CAT } & \multirow[t]{2}{*}{ TCAT } & \multicolumn{3}{|c|}{ Não CAT } & \multirow[t]{2}{*}{ TNC } \\
\hline & $\mathbf{F}$ & so & $\mathrm{C}$ & & $\mathrm{F}$ & so & $\mathrm{C}$ & \\
\hline $\begin{array}{l}\text { I) Casamento entre pessoas do } \\
\text { mesmo sexo }\end{array}$ & 49.54 & 24.77 & 25.69 & 100 & 44.44 & 14.53 & 41.03 & 100 \\
\hline $\begin{array}{l}\text { II) Adoção de crianças por casais } \\
\text { homossexuais }\end{array}$ & 56.31 & 18.45 & 25.24 & 100 & 66.34 & 7.92 & 25.74 & 100 \\
\hline III) Descriminalização das drogas & 11.32 & 17.92 & 70.75 & 100 & 13.91 & 13.04 & 73.04 & 100 \\
\hline $\begin{array}{l}\text { IV) Pena de morte para certos } \\
\text { tipos de crime }\end{array}$ & 46.67 & 15.24 & 38.1 & 100 & 41.88 & $14 \cdot 53$ & 43.59 & 100 \\
\hline V) Maioridade penal aos 16 anos & 42.72 & 9.71 & 47.57 & 100 & 41.38 & 8.62 & 50 & 100 \\
\hline $\begin{array}{l}\text { VI) Fazer queimadas para plantar } \\
\text { e renovar os pastos }\end{array}$ & $15 \cdot 38$ & 8.65 & 75.96 & 100 & 13.68 & 4.27 & 82.05 & 100 \\
\hline $\begin{array}{l}\text { VII) Reservas de vagas em } \\
\text { concursos públicos e na } \\
\text { universidade para os negros }\end{array}$ & 71.15 & $15 \cdot 3^{8}$ & 13.46 & 100 & 62.39 & 20.51 & 17.09 & 100 \\
\hline
\end{tabular}

F- Favorável; SO - Sem Opinião; C- Contra; TCAT. Total Cat; TNC. Total não Cat Fonte: Os autores.

Ainda a respeito da "Orientação Ideológica, a Tabela 8 dá destaque ao efeito do CAT sobre cada determinante da orientação ideológica dos egressos que compôs o índice, representado na segunda linha, e apresenta, também, os efeitos controlados pelas características individuais e familiares destes egressos - as colunas representam as mesmas questões da tabela anterior. É possível observar que não houve efeito estatisticamente significante do CAT sobre nenhuma variável, e que a relativa homogeneidade intergrupos, verificada na distribuição de frequências, resulta em baixos efeitos: para valores que podem variar entre +1 e -1, o maior efeito (sem controle) foi 0,177. Ressalta-se apenas a variável de gênero masculino que teve efeito positivo e estatisticamente significante sobre o item VII, que representa a opinião favorável às reservas de vagas para negros em concursos públicos e universidades. 
Tabela 8 - Efeito do CAT na orientação ideológica dos egressos, por tipo.

\begin{tabular}{llllllll}
\hline & I) & II) & III & IV & V) & VI) & VII) \\
\hline Cat & 0.177 & -0.112 & -0.0608 & 0.144 & 0.0293 & 0.0885 & 0.0954 \\
& $(1.02)$ & $(-0.66)$ & $(-0.42)$ & $(0.79)$ & $(0.15)$ & $(0.67)$ & $(0.67)$ \\
Idade & -0.00369 & -0.00397 & -0.00337 & -0.0197 & -0.0147 & 0.00433 & -0.0131 \\
& $(-0.27)$ & $(-0.29)$ & $(-0.30)$ & $(-1.38)$ & $(-0.99)$ & $(0.42)$ & $(-1.18)$ \\
Genero & -0.0434 & -0.208 & 0.143 & -0.193 & -0.0633 & -0.0947 & $0.429^{* *}$ \\
& $(-0.25)$ & $(-1.20)$ & $(1.00)$ & $(-1.08)$ & $(-0.34)$ & $(-0.73)$ & $(3.06)$ \\
Negro & -0.350 & -0.319 & 0.0765 & 0.207 & 0.0810 & -0.133 & -0.0868 \\
& $(-1.90)$ & $(-1.77)$ & $(0.50)$ & $(1.08)$ & $(0.40)$ & $(-0.96)$ & $(-0.58)$ \\
Irmãos & -0.0117 & -0.0489 & -0.0495 & -0.0175 & -0.000834 & 0.0466 & 0.0194 \\
& $(-0.31)$ & $(-1.34)$ & $(-1.61)$ & $(-0.45)$ & $(-0.02)$ & $(1.67)$ & $(0.64)$ \\
escol_pais & -0.0840 & -0.0838 & -0.0112 & -0.0470 & -0.0722 & 0.00945 & -0.0402 \\
& $(-1.80)$ & $(-1.82)$ & $(-0.29)$ & $(-0.96)$ & $(-1.41)$ & $(0.27)$ & $(-1.05)$ \\
Renda & 0.000148 & 0.0000315 & -0.000128 & $0.000436^{*}$ & 0.000326 & -0.000210 & -0.000200 \\
& $(0.72)$ & $(0.16)$ & $(-0.75)$ & $(2.02)$ & $(1.41)$ & $(-1.33)$ & $(-1.17)$ \\
\multirow{2}{*}{ cons } & 0.373 & $1.058^{* *}$ & -0.267 & 0.0465 & 0.0366 & $0.704^{*}$ & $0.793^{* *}$ \\
& $(1.06)$ & $(3.00)$ & $(-0.91)$ & $(0.13)$ & $(0.09)$ & $(2.59)$ & $(2.70)$ \\
N & 127 & 111 & 123 & 126 & 124 & 125 & 125 \\
\hline
\end{tabular}

$t$ statistics in parentheses. ${ }^{*} p<0.05,{ }^{* *} p<0.01,{ }^{* * *} p<0.001$

Fonte: Os autores.

A categoria "Fixação no Território" foi aferida como medida simples, constituindo-se de uma única variável. Deste modo, diferentemente das medidas compostas (índices) não cabe decomposição por itens.

\section{Considerações finais}

No presente texto, examinamos os impactos de uma metodologia designada CAT Conhecer, Analisar e Transformar, implementada no primeiro ciclo do ensino fundamental de escolas rurais em dois territórios da região semiárida da Bahia, ao longo de anos. Aferimos estes impactos da metodologia (também designada de Projeto CAT) no desenvolvimento de habilidades não associadas ao rendimento escolar, reunidas nas categorias "Ativismo Social", "Importância da Escola" e "Orientação Ideológica". Lançando mão do corpo teórico, incluindo as referências centrais do referido projeto, intencionávamos verificar o grau de resistência que o projeto impõe à tendência reprodutivista do sistema de ensino.

Os resultados positivos encontrados nas categorias "Ativismo Social" e "Importância da Escola" sugerem que: i) egressos CAT atribuem à escolarização um papel mais importante em seu processo formativo. Com maior frequência, egressos CAT identificam suas experiências 
em sala de aula com o desenvolvimento de variadas práticas sociais, ou seja, dão sentido à prática pedagógica que ultrapassa a visão da escolarização como um processo apartado de suas vidas; ii) egressos CAT têm maior participação na vida comunitária, sobretudo em atividades extraescolares e religiosas. Em comparação com egressos não-CAT, eles têm maior predisposição a valer-se do tempo livre para atuação direta na vida pública. Nas outras duas categorias, no entanto, não há diferenças estatisticamente significativas entre os egressos CAT e não-CAT.

A análise conjunta desses resultados sugere que o CAT oferece resistência local à tendência de reprodução cultural do sistema de ensino. Contudo, é necessário situá-la e apontar seu grau de influência. Sabe-se que o sistema de ensino regular tende a oferecer uma posição passiva ao estudante e a focar sua atuação na transmissão de informação para memorizaçãoe, frente a estas tendências, oCAT interpõe-se ao formar sujeitos mais inclinados à participação comunitária e que relacionam suas experiências pedagógicas ao seu percurso fora do ambiente escolar. Por outro lado, a localização dos resultados positivos da categoria "Ativismo" nas variáveis "atividade escolar" e "atividade religiosa" sugerem prudência na interpretação dos resultados, pois são duas áreas de atuação vinculadas a instituições tradicionalmente de forte cunho reprodutivista. Este apelo à prudência é reforçado pela ausência de efeito significativo na categoria "Orientação Ideológica", cujas questões tocam pontos sensíveis do debate público (algumas explicitamente trabalhadas pelo projeto) e que, no entanto, apresentam tendências de respostas intergrupos muito similares.

Em outros termos, há evidências de que egressos CAT tendam a participar mais da vida comunitária, mas não encontramos indícios seguros de diferenças ideológicas significativas em relação ao meio - diferenças que, em tese, dariam contribuição importante na construção de outros sentidos comuns para a convivência no semiárido. Considere-se, porém, que se trata, sobretudo, de adolescentes (média de idade em torno de 16 anos) ainda em processo formativo.

Se os dados referentes à "Orientação Ideológica" são tímidos, o mesmo não ocorre com os que tratam da "Importância da Escola". Egressos CAT atribuem ao período de escolarização entre $01^{\circ}$ e $5^{\circ}$ ano (o período de atuação do projeto, portanto) grande importância em seu processo de formação, diferente dos egressos não-CAT. Além disso, as contribuições do projeto, identificadas pelos egressos que têm diferenças estatisticamente significativas, compõem um leque diversificado de dimensões pedagógicas e campos de atuação, detalhados 
anteriormente. Os egressos CAT estão mais presentes na vida comunitária, em campos mais diversos, e atribuem às experiências pedagógicas vividas anteriormente junto ao projeto CAT um papel importante para esta participação, que pode ser muito enriquecedora para sua formação presente. Manifestações por direitos e práticas artísticas coletivas, por exemplo, permitem ao egresso convívio mais intenso com diferenças e conflitos em um estágio de formação em que o relativo exclusivismo da família na socialização do sujeito começa a entrar em cheque.

Em suma, a ausência de efeito estatisticamente significante na Orientação Ideológica dos egressos CAT não nos parece uma deficiência do projeto, tendo em vista o ciclo de escolarização em que atua: é apenas um ganho desejável, desde o início pouco provável e que, de fato, não se tem. Por outro lado, os ganhos em Ativismo e Importância da Escola encontrados nesta avaliação podem abrir ao egresso um campo de possibilidades e vivências que contribuam para uma formação mais liberal, do ponto de vista moral, e mais combativa, do ponto de vista político, justamente em um período privilegiado para experimentar tais experiências: a adolescência, quando os capitais extrafamiliares começam a se tornar mais acessíveis.

\section{Referências}

BONNEWITZ, Patrice. Primeiras lições sobre a sociologia de Pierre Bourdieu. Petrópolis: Vozes, 2003.

BOURDIEU, P.; PASSERON, J.-C. A reprodução: elementos para uma teoria do sistema de ensino. Rio de Janeiro: Francisco Alves, 1982.

BOURDIEU, Pierre. Espaço social e a gênese das "classes". In: O poder simbólico. Rio de Janeiro: Bertrand Brasil, 1989, pp. 133-161. $149-168$

Espaço Social e poder simbólico. In: Coisas ditas. São Paulo: Brasiliense, 2004, pp.

Os três estados do capital cultural. In: Escritos de Educação. (Org.) Maria Alice Nogueira e Afrânio Catani. Petrópolis, RJ: Vozes, 2007, pp. 71-79.

DURKEIM, E. Educação e Sociologia. São Paulo: Melhoramentos, 1973. 91 p.

FREIRE, Paulo. Pedagogia do Oprimido. 42. ed. Rio de Janeiro: Paz e Terra, 2005. 
LORDELO, J.A.C e DAZZANI, M.V. Estudos com estudantes egressos. Concepções e possibilidades metodológicas na avaliação de programas. Salvador: Edufba, 2012.

NOGUEIRA, Cláudio Marques Martins; NOGUEIRA, Maria Alice. A sociologia da educação de Pierre Bourdieu: limites e contribuições. Educ. Soc., Campinas, v. 23, n. 78, p. 15-35, Abril de 2002 . Disponível em <http://www.scielo.br/scielo.php?script=sci arttext\&pid=S0101$73302002000200003 \&$ lng=en\&nrm=iso>. acessado em 12 Maio de 2017. http://dx.doi. org/10.1590/S0101-73302002000200003.

ROSA, Dora Leal. A Escola e a Formação do Sujeito Moral: Possibilidades e Limites da Instituição Escolar. In: Revista da FACED, nº 05, 2001. Edufba, Salvador. pp 13-26.

TOSCANO, M. Sociologia Educacional. Petrópolis: São Paulo, 2001. 244 p.

\begin{abstract}
This article reports results obtained from a project developed in Bahia's semiarid rural school scope, outside the institution's walls. Freirean inspired methodology was grounded on social learning referenced in the student's reality. According to this methodology's principles, the student must acknowledge, analyze and transform (CAT Project) reality in which he or she lives. Knowledge's contextualization is crucial for the student to resignify knowledges and values, learn to live, read and intervene in his or her reality. This active subject would rise from teachers'continuous formation, contextualized courseware and adoption of pedagogical practices and democratic management. As another institutionalized product, the aim was to convince cities to separate resources from their local budgets to use that methodology in contextualized rural education. The analysis technique which produced this discussion was anchored in a statistical-econometric model of regression analysis in order to isolate the program's effect from data collection between experimental and control groups. Results showed that there were significant statistical diferences between schools which adopted and didn't adopt the methodology. It is suggested that contextualized education might be justified by the results obtained from objective indicators beyond the school's walls, by a principle of the subject's right to understand his or her place and the relations established between him or herself and his/her several life dimensions: social, political, economic, environmental and cultural.
\end{abstract}

Keywords: rural education; contextualized education. 